\title{
Development of a thermo diagnostic device for monitoring the technical condition of bearings and its comparison with other control methods
}

\author{
Eriks Ozolins \\ Aeronautics Institute of Riga Technical University, Riga, Latvia \\ Eriks.Ozolins@rtu.lv \\ Anton Orlov \\ Aeronautics Institute of Riga Technical University, Riga, Latvia \\ antons.orlovs@gmail.com \\ Ilmars Ozolins \\ Aeronautics Institute of Riga Technical University, Riga, Latvia \\ Ilmars.Ozolins@rtu.lv
}

\begin{abstract}
Within the Institute of Aeronautics, a working diagnostic device was developed, which is able to perform remote temperature monitoring of bearings with a set periodicity, as well as warns the technical staff about temperature rises above the operating limit. The article describes the components of the device and the conditions for their selection. Relatively longterm experimental tests were performed to fully test the device and verify its performance. In the course of these tests, a comparison of the developed device with other bearing control devices was also made in order to be able to draw conclusions as to whether our device is effective in controlling the technical condition of bearings. This article summarizes the results of these researches.
\end{abstract}

Keywords: thermo diagnostic device, temperature, bearing technical condition, thermocouple, controller.

\section{Introduction}

The performance and safety of any equipment and structures depends directly on their technical condition. As the structures are exposed to various adverse processes and conditions during operation, sooner or later, various defects appear in the structural units and elements. If these defects are not detected and controlled in time, the defect of a small part can lead to the out of order of an expensive and complex structure, mechanism or equipment, unplanned downtime and expensive repairs. Therefore, timely detection of defects and damage is a very important and topical question [1]. 
There are many different methods and types of technical condition control. In many industries, where defects and damage to parts and structures cannot have serious consequences, repairs are still only carried out when equipment is out of order. However, the complexity and cost of modern machinery and equipment are forcing the search for and introduction of new, more cost-effective approaches to monitoring the technical condition of equipment.

For example, as technology advances, more and more tools are emerging that can carry preventive maintenance and replacement of parts. In this approach, the periodicity of replacement of parts and mechanisms can be determined by collecting data and performing statistical analysis. Preventive maintenance reduces the likelihood that the machine will go out of order at an inopportune moment. However, preventatively change of details often also comes at a cost and disadvantage. This is because, on the one hand, a part may break unexpectedly without the time allotted to it, but on the other hand, a part that has reached its allotted time and needs to be replaced is in fact still in good technical condition and could still work for some time. As a result, the so called, predictive maintenance approach is emerging and evolving [2], [3]. This approach means that the equipment (the most important structural elements) has built-in or attached sensors that measure various parameters (temperature, vibration level, deformation level, pressure, etc.) in real time with a certain periodicity and collect statistical information for further processing and analysis, as well as taking into account sensor readings, may alert technical staff if any of the parameters begin to exceed the maximum allowable level. One method of this approach is temperature monitoring. For example, if, under stable operating conditions, the temperature in the bearing area rises above the upper limit of the operating temperature, this often indicates the development of a bearing malfunction and the approach of a defect. Upon receipt of such warnings, the technical staff may carry out a more detailed inspection of the bearing in good time, using other nondestructive testing methods, and decide on the replacement of the bearing, depending on the results obtained. In this way, it is possible to change only parts that show signs of wear or damage. Thus, such continuous monitoring determines the onset of component defects, which means that maintenance should only be performed as necessary. With this type of approach, unplanned downtime is reduced or eliminated, thus increasing efficiency and reducing costs.

\section{Development of the device and its components}

A predictive diagnostic device was developed within the Institute of Aeronautics. The principle of operation of this device is based on temperature measurement. This device allows the bearing temperature to be measured at specified intervals during operation, to compile and store this information for later processing and analysis, and to alert the technical staff if the temperature rises above the operating limit.

The main concept was to make a device that would cost cheaply, but with the same variety of features and capabilities as devices made by other large manufacturers, such as SKF, INA, KOYO. It must also be taken into account that the device must be small in size and resistant to shocks.

The developed thermo diagnostic device consists of the following components: box, controller, battery, sensor (Fig. 1). 


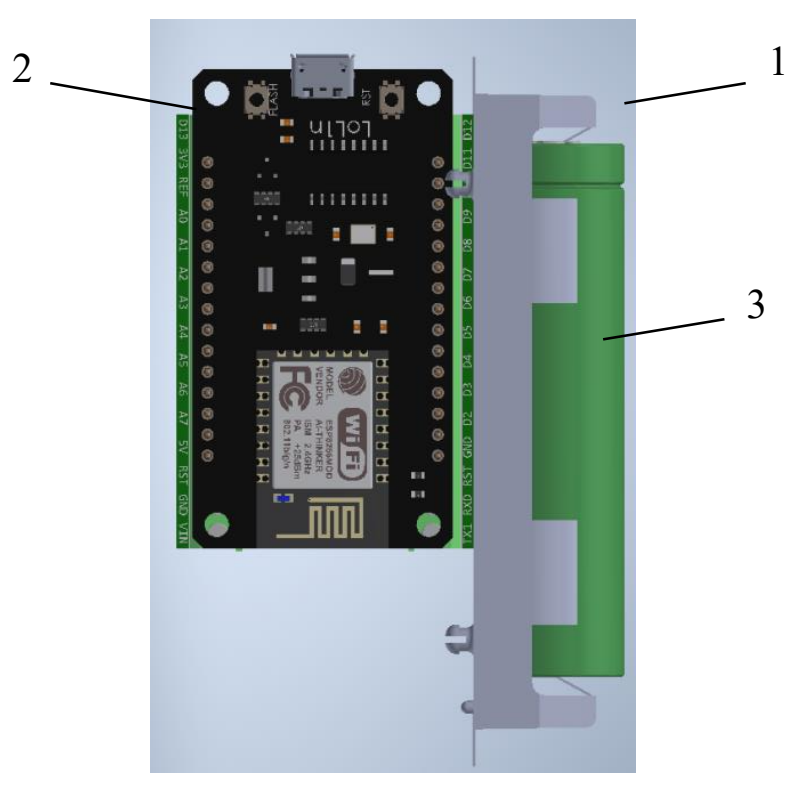

Figure 1. Overview of the thermo diagnostic device: 1 - box; 2 - controller; 3 - battery.

\subsection{Box}

The box must be both impact-resistant and lightweight. Therefore, in the beginning, using Inventor 2019 and a 3D printer, box was made in which the battery pack could be placed together with the controller. However, the box proved to be not very durable and cracks appeared in the box after the first fall. Therefore, temporarily, an industrial distribution box was used, which is twice as large and therefore its placement possibilities are limited. Neodymium magnets were used to attach the box to the equipment, which allows it to be moved in a convenient place, as well as easily removed if it needs to be transferred to another device (Fig. 2).
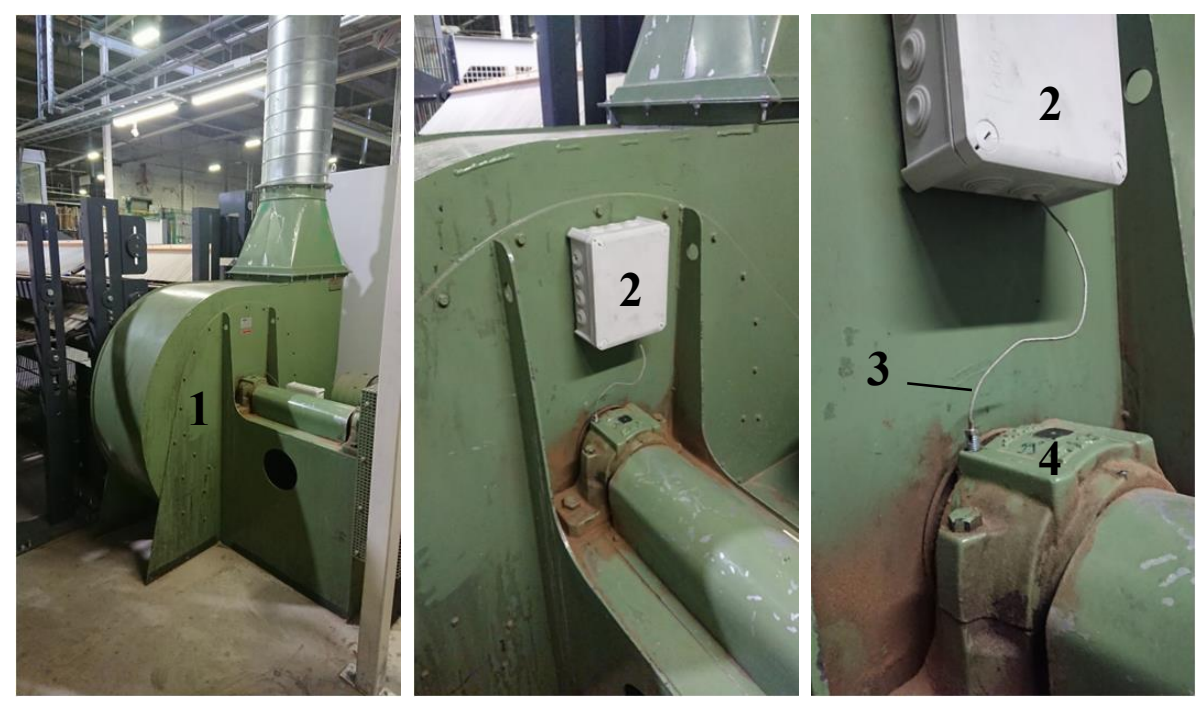

Figure 2. Location of the box with the device inside on the vacuum equipment: 1 - vacuum equipment; 2 - box; 3 - thermocouple; 4 - bearing housing. 


\subsection{Controller}

In our case, the device is controlled by the ESP8266 NodeMCU controller with built-in Wi-Fi function (Fig. 3). This controller is designed on the basis of Arduino, with digital and analog inputs. It should be mentioned that Arduino is an electronic designer and a convenient platform for rapid development of electronic devices for beginners and professionals [4], [5]. The platform is very popular all over the world due to its convenient and simple programming language, as well as its open architecture and program code. The device is programmed via USB without the use of programmers. You can download a program to your Arduino processor that will manage the device according to a certain algorithm. For Arduino controllers, the memory is $2 \mathrm{~KB}$. However, not all of the free memory (RAM) is typically used. The code portion of the device we develop takes up only $30 \%$ of the total memory, despite the fact that it communicates with the server, transfers data, and cyclically checks it.

The programs are written in a simplified $\mathrm{C}$ and $\mathrm{C}++$ programming language with commands loaded from the ready-made library, thus making programming easier.

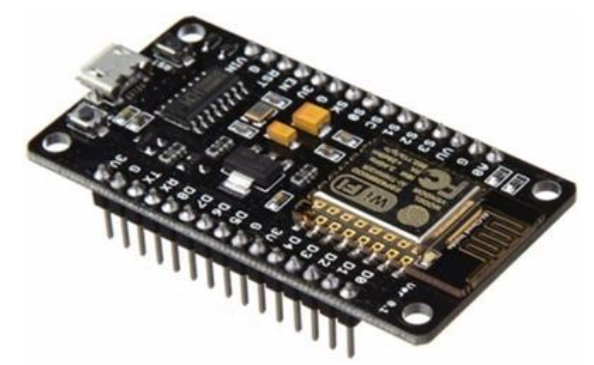

Figure 3. ESP8266 NodeMCU controller.

A "Blynk" server is used to monitor the temperature remotely, as well as receive reports of exceeding it. "Blynk" is an open-ended project that allows you to connect to a server and transfer data from a variety of sensors. The server allows storing data for up to one year with the possibility to obtain it in the form of an Excel file with date attachment, as well as allows creating a ready-made mobile application. The "Blynk" platform is needed to be able to analyze the obtained data and see live how the parameters change (Fig. 4).

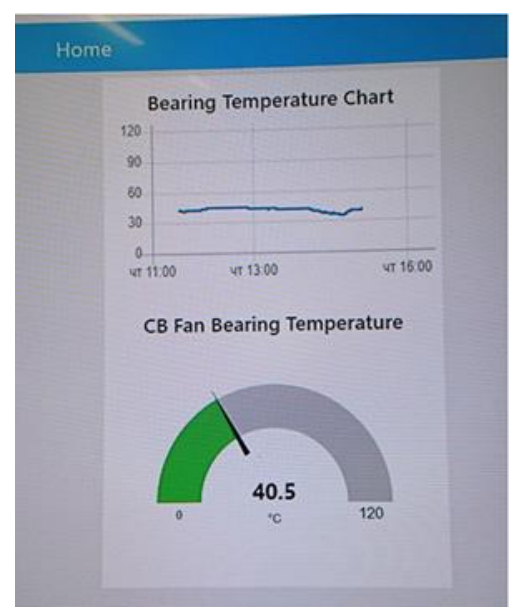

Figure 4. Temperature data on the screen live. 
Excel is used for further data processing. The operating temperature exceeded message was set to $80{ }^{\circ} \mathrm{C}$. When the temperature is exceeded, an alert will be sent to E-mail or phone notifications.

One major problem was immediately encountered during the development of the device. The signal strength of Wi-Fi technology makes it difficult to place the device. The network either needs to be enlarged with additional routers ("BRIDGE" function), or the devices must be placed close to each other or with a direct signal router. Although there are better solutions in the industrial field (LORA WAN) that can transfer data over longer distances than Wi-Fi technology, the Wi-Fi technology option was chosen because it is easy to install and cheaper. As well as the connection to the server is easily replaced by the use of flash memory.

\subsection{Batteries}

The Arduino power supply is built in a special way, allowing you to work with different energy sources, and with different current and voltage values. To increase the mobility of the device, two Li-Ion batteries with a capacity of $2500 \mathrm{mAh}$ were used. Diameter is $18 \mathrm{~mm}$, length $65 \mathrm{~mm}$. The main disadvantage of batteries is their capacity, which is limited only by price.

\subsection{Sensors}

The temperature is measured with a temperature-sensitive elements - a sensor, which must be installed as close as possible to the object to be controlled, in our case, it is the outer ring of the bearing. The closer the sensor is to the controlled object, the more accurate the temperature measurements will be. There are several types of temperature sensors: a thermistor, a thermocouple.

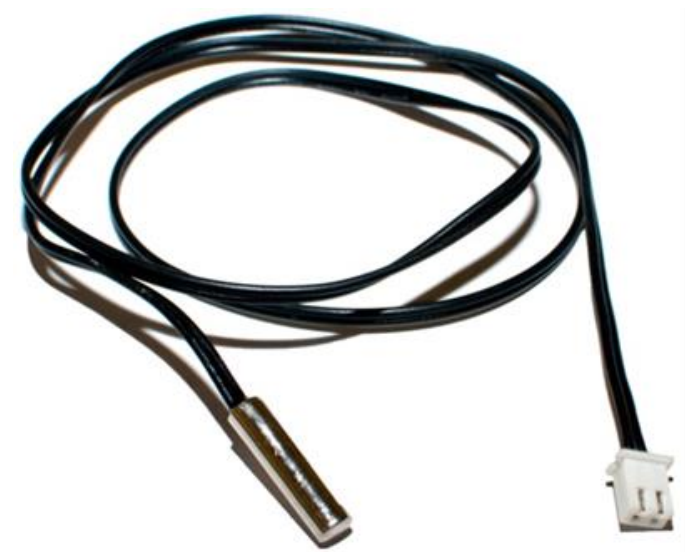

a)

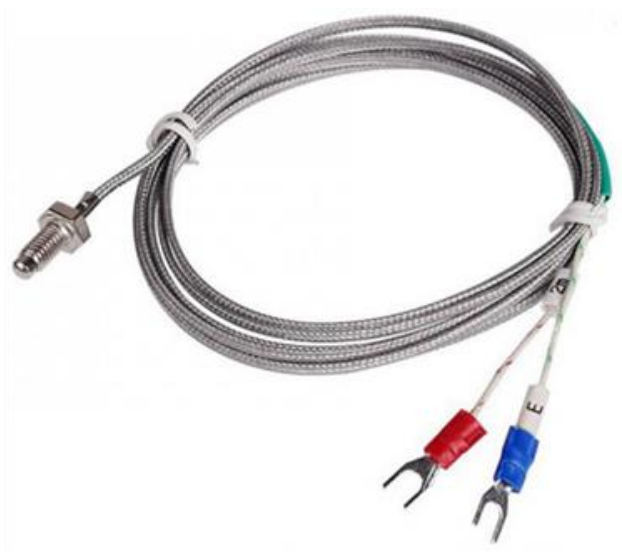

b)

Figure 5. Types of sensors: a) - thermo resistor; b) - thermocouple.

A thermistor (Fig. 5a) is a semiconductor device whose resistance depends on its temperature. The operating principle is related to the semiconductor principle. As the resistance of a semiconductor is proportional to temperature, a proportionality factor is used, which determines on how many ohms or percent the resistance of the element changes if the temperature rises by 1 degree Celsius. 
There are thermistors in different temperature ranges: low temperature thermistors (up to $170 \mathrm{~K})$, medium temperature thermistors $(170-510 \mathrm{~K})$ and high temperature thermistors (900$1300 \mathrm{~K}$ ). The housing of the element can be made of plastic, glass, metal or ceramic.

Thermistor elements with resistance values from $100 \mathrm{ohms}$ to $5 \mathrm{M}$ ohms and with tolerances of $\pm 1 \%, \pm 2 \%$ are available. Accuracy can reach up to $\pm 0.1^{\circ} \mathrm{C}$ [6].

A thermocouple (Fig. 5b) is basically a pair of different metal wires that are welded in one place. To ensure the durability of the thermocouples, they are protected from mechanical damage. Thermocouples are usually equipped with special connectors for quick and easy connection and disconnection. The operating principle is based on the Seebeck effect or, in other words, the thermoelectric effect. When the ends of the wire are at different temperatures, a potential difference occurs between them, which is proportional to the temperature difference. As the thermocouple consists of two wires made of different metals, therefore, there will be different potential differences that arise between the ends of different conductors [7].

The main advantage of a thermocouple is as follows: it allows you to measure the temperature up to $+1260{ }^{\circ} \mathrm{C}$. But the disadvantage is the accuracy of the temperature readings. The reading error of the K-Type thermocouple is $+/-2.2^{\circ} \mathrm{C}$ [8]. Also, the signal from it is weak, so an amplifier is needed.

The digital sensor is connected directly to the controller and the device takes up less space. But it can only measure up to $+125^{\circ} \mathrm{C}$, and it can reach the highest accuracy $\left(+/-0.5^{\circ} \mathrm{C}\right)$ in the temperature range from $-10^{\circ} \mathrm{C}$ to $85^{\circ} \mathrm{C}$ [9].

In our case, there is no need to measure the bearing temperature with an accuracy of tenths of a degree. In addition, it turned out that the end of the thermocouple could be screwed in instead of the lubrication nipple using an adapter to gain access closer to the bearing (Fig. 6). Therefore, for the installation of the thermocouple, there was no need to make a special hole in the housing opposite the bearing. Therefore, in our case, the thermocouple was chosen.

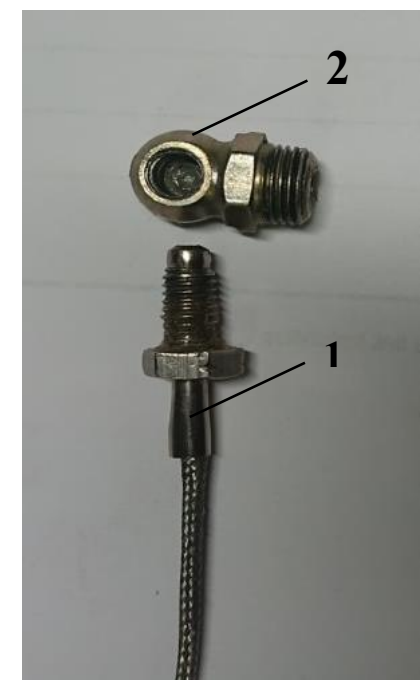

a)

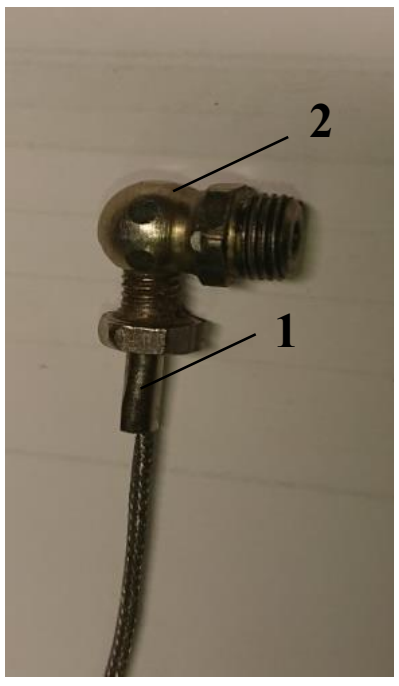

b)

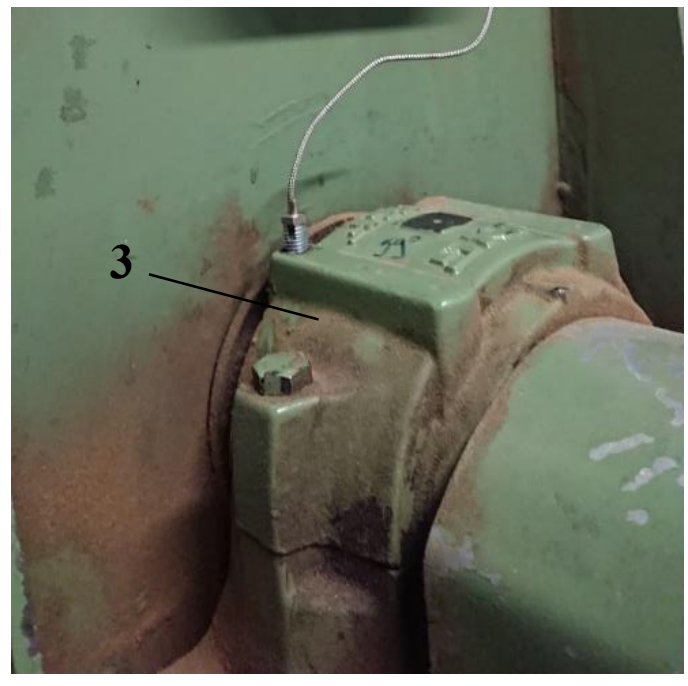

c)

Figure 6. Thermocouple end with adapter:

a) - in a disassembled state; b) - in a assembled state; c) - the thermocouple is installed in the housing; 1 - thermocouple end; 2 - adapter; 3 - bearing housing. 


\section{Description of the experiment}

A vacuum machine with two SKF 22313EK tapered double row bearings with spherical rollers was used for the experimental tests. Bearing speed is $1180 \mathrm{rpm}$. The bearings are lubricated with lithium-based EP2 grease. The outdoor air temperature is $15^{\circ} \mathrm{C}$. The sensors of the device were only attached in the housing to one of these bearings, which during the experiment allowed measuring the operating temperature of this bearing (Fig. 7). The bearing to be tested is located inside the housing. The bearing scheme and parameters are given in Figure 7c [10].

The experiments lasted for about 2 months. During the experiment, the vacuum unit was operated continuously 24 hours a day, 7 days a week. During the experiment, the operating temperature of the bearing was measured and recorded 4 times a day.

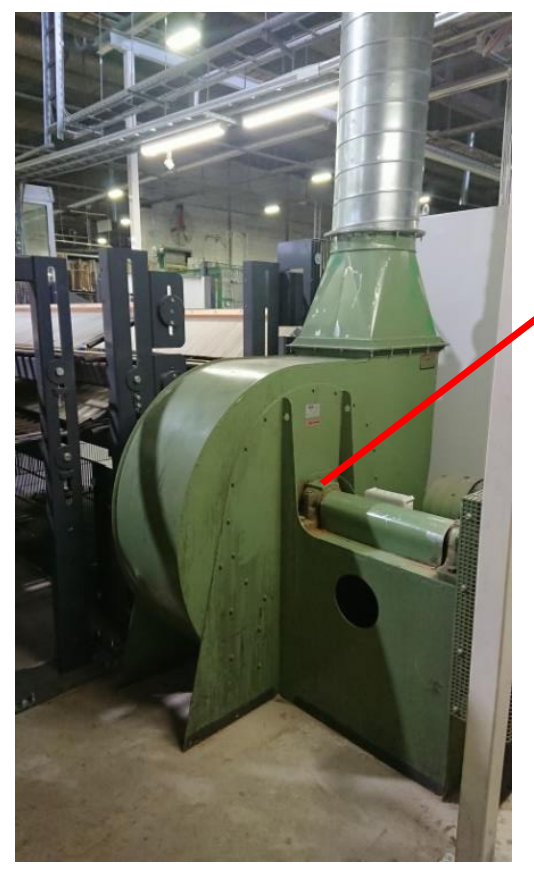

a)

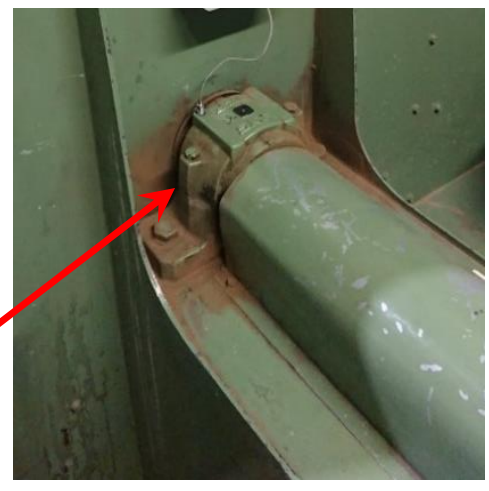

b)

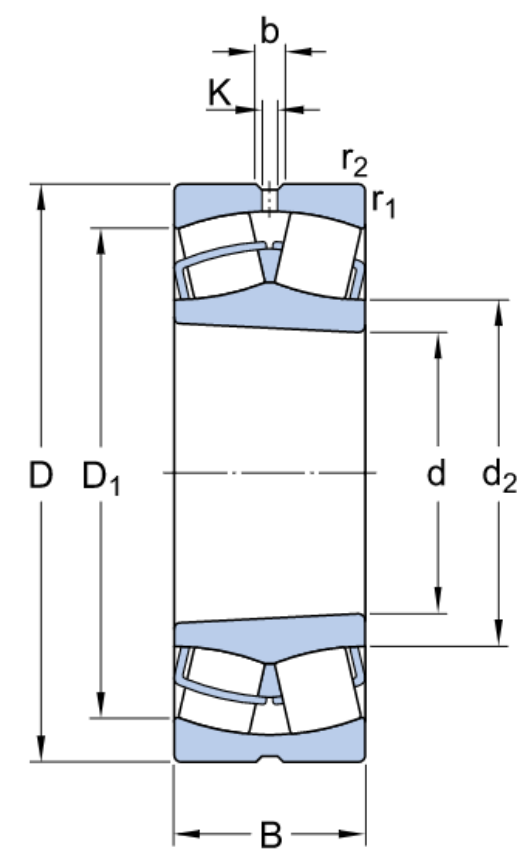

c)

Figure 7. The equipment used to perform the test measurements: $\mathrm{a}$ - vacuum equipment overview; $\mathrm{b}$ - bearing housing; $\mathrm{c}$ - bearing scheme; $\mathrm{d}=65 \mathrm{~mm} ; \mathrm{D}=140 \mathrm{~mm} ; \mathrm{B}=48 \mathrm{~mm} ; \mathrm{d} 2 \approx 81.6 \mathrm{~mm} ; \mathrm{D} 1 \approx 118 \mathrm{~mm} ; \mathrm{b}=8.3 \mathrm{~mm} ; \mathrm{K}=4.5$ $\mathrm{mm} ; \mathrm{r} 1 \mathrm{~min}, \mathrm{r} 2 \mathrm{~min}=2.1 \mathrm{~mm}$.

\section{Summary and analysis of experiment results}

During the experiment, data was collected and sent to the server. Next, this data was processed with the DataScene program so that the results could be viewed graphically. To make it easier to view and analyse the results, the average operating temperature was calculated for each day. Information for two months was examined and compared: February and March.

As far as the bearing grease was replaced in February and the worn belts connecting the electric motor to the shaft were replaced, two important measurements are visible in February: point 02.02.20 and the range from 15.02.20 to 16.02.20 (Fig. 8). 


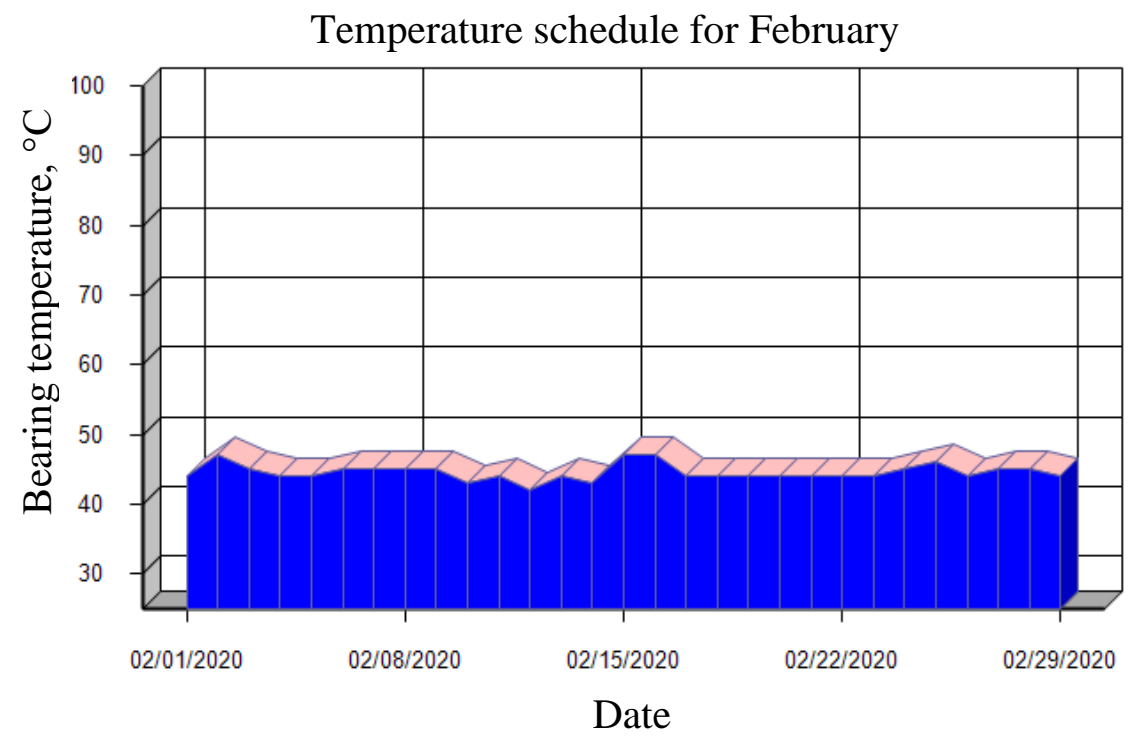

Figure 8. Temperature measurements in February.

The temperature increase in 02.02.20 is due to belt replacement and tensioning. Most likely, the increase in bearing temperature indicates an increase in the load on the shaft after the installation of new belts. Over time, the new belts stretched and the load decreased again.

The temperature increase on 15.02.20 and 16.02.20 is due to the change of grease in the bearings. On February 15, the bearings were lubricated with EP-2 grease. The amount of grease was 170 grams. After lubrication, the temperature can rise for up to three days. This is due to the fact that the grease may be too much and it takes time for it to settle in place. Therefore, during these two days, the grease formed an increased resistance and the temperature was elevated.

In March, for the most part, temperature values remained almost unchanged (Figure 9).

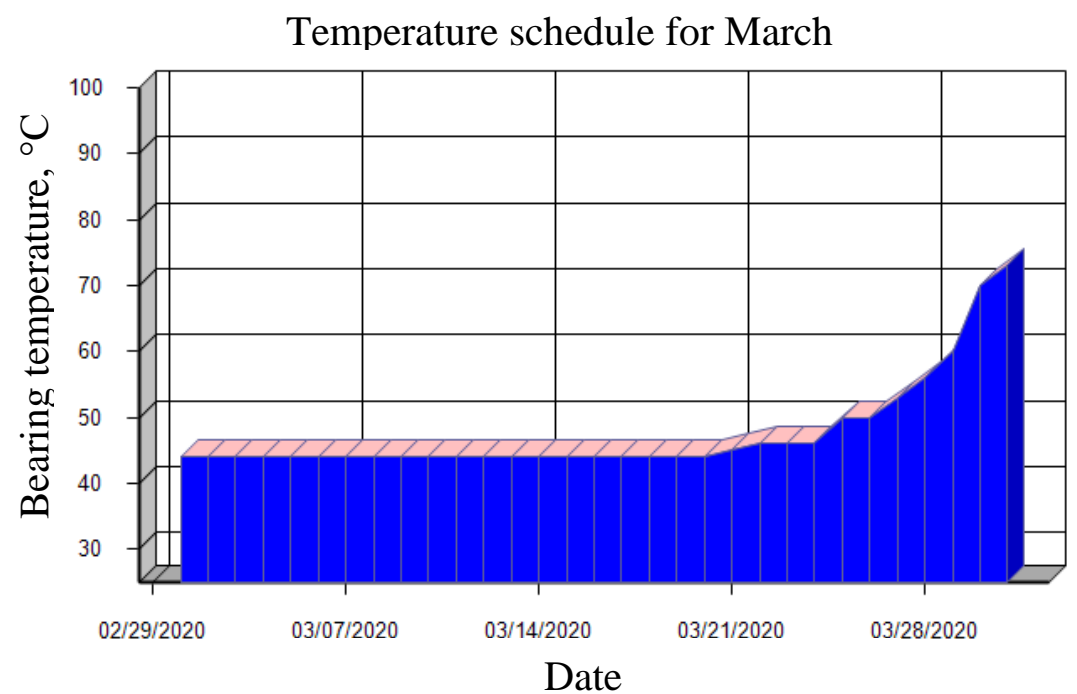

Figure 9. Temperature measurements in March. 
However, the last week of March saw a rise in temperature. Initially, it was associated with an increase in outdoor temperature and was therefore not addressed. Later, the rise in temperature became already significant. Therefore, vibrations in the axial direction (12.9 $\mathrm{mm} / \mathrm{s}$ ) and in the radial direction $(15.3 \mathrm{~mm} / \mathrm{s})$ were measured (Fig. 10), which turned out to be above normal, because after the norm the warning level is $4.5 \mathrm{~mm} / \mathrm{s}$ and in a dangerous state 7, $1 \mathrm{~mm} / \mathrm{s}$. Vibration norms are described in the literature [11], [12].
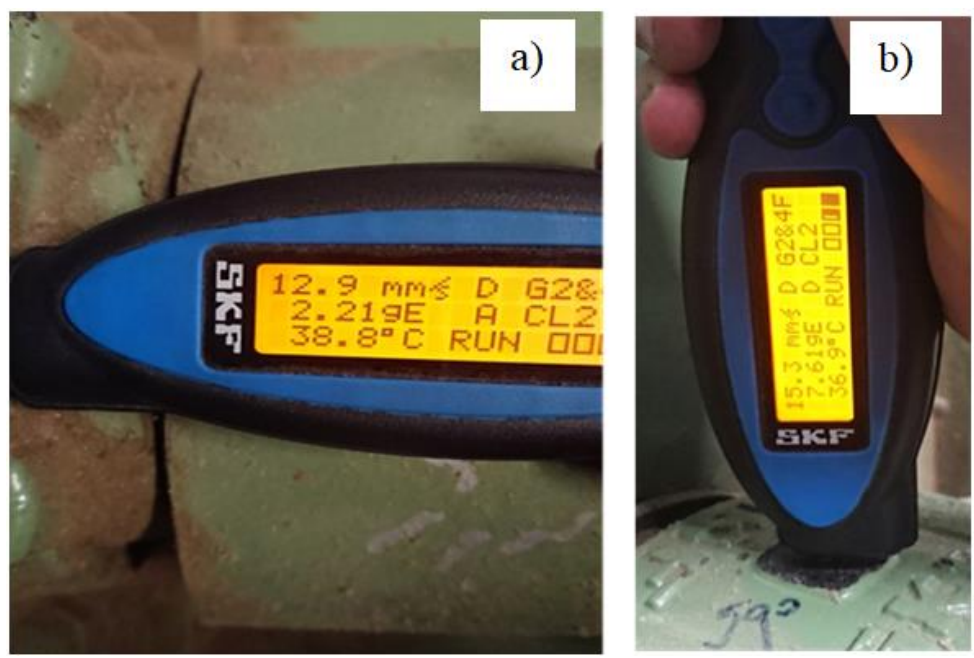

Figure 10. Vibration transfer:

a) - in the axial direction; b) - in the radial direction.

There was also an uncharacteristic noise coming from the bearings. The machine was stopped. During the visual inspection, cracks were revealed in the housing of the vacuum device (Fig. 11). Therefore, the linear arrangement of the bearings changed and also the distance between the rollers and the outer ring. As well as the shaft bent, creating an additional load.

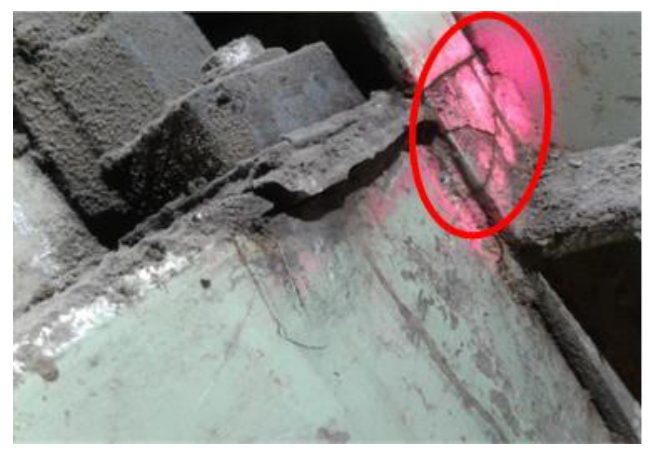

Figure 11. Cracks in the equipment housing.

Repairs were carried out. The cracks and the area around the cracks were cut out. A $20 \mathrm{~mm}$ thick metal plate was welded under the bearings, in which holes were drilled for fixing the bearing housings. The bearings were also replaced. The work was hampered by the presence of dust. Cutting and welding were very flammable. In total, the equipment stood for 8 hours. 
After the repairs were completed, the unit was started and the first thing that was observed was a decrease in the bearing temperature, but the temperature was above $50{ }^{\circ} \mathrm{C}$. This indicated errors that had been made during repairs or the installation of new bearings. Initially, the placement of the new plate was checked, but the test results showed that the plate was welded correctly and accurately in its intended place.

It was then checked that the bearing was installed and secured correctly. To check this, it is necessary to determine the average gap between the bearing rollers and the outer ring, as the size of the gap is one of the factors that can affect the bearing temperature (Fig. 12c).

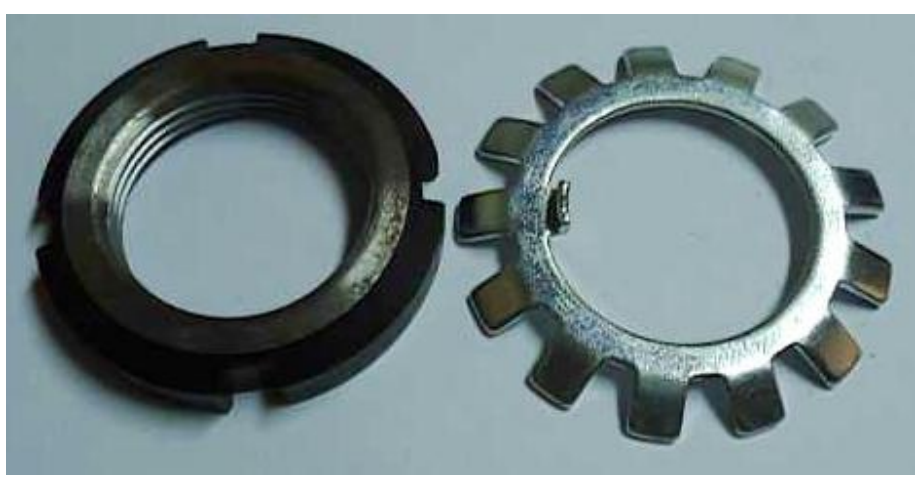

a)

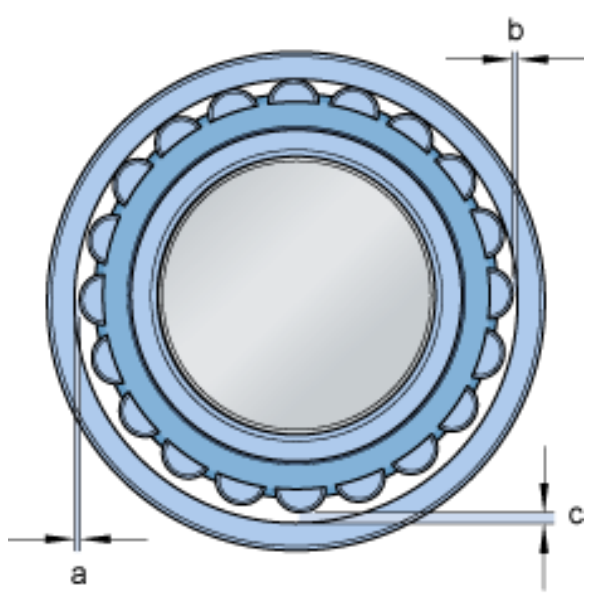

c)

Figure 12. Bearing fixing elements and bearing gap measuring points:

a) - round nut; b) - locking spring washer; $c$ ) - bearing scheme with gap measuring points.

The average gap is calculated according to the following formula:

$$
V=0,5 \cdot(a+b+c)
$$

where a - the distance measured in the position for 9 hours;

$\mathrm{b}$ - the distance, which is measured in position for 3 hours;

$\mathrm{c}$ - the distance measured under the lower roller, which is in position for 6 hours.

The size of the gap between the outer ring and the unloaded rollers must always be measured. The touch should be inserted easily and without excessive force. The force applied to the touch is only needed to overcome the weight of the roller. Measurements had to be made on both rows of rollers. The following results were obtained in one of the rows of rollers: $\mathrm{a}=0.009 \mathrm{~mm}, \mathrm{~b}=0.010 \mathrm{~mm}, \mathrm{c}=0.011 \mathrm{~mm}$. According to formula (1), the following average gap was obtained:

$$
\mathrm{V}=0,5 \cdot(0,009+0,010+0,011)=0,015 \mathrm{~mm}
$$

The size of the average gap has turned out to be outside certain limits $(0.025 \mathrm{~mm} \ldots$ $0.035 \mathrm{~mm})$. So, the reason was found why the bearing had an elevated operating temperature. After the bearing was properly tightened using the round nut (Fig. 12a) and the locking spring washer with teeth (Fig. 12b), the gaps were measured again. Now the gaps between the two 
rows of rollers were almost identical: $\mathrm{a}=0,0018 \mathrm{~mm}, \mathrm{~b}=0.020 \mathrm{~mm}, \mathrm{c}=0.025 \mathrm{~mm}$. According to formula (1), the size of the average gap was calculated:

$$
V=0,5 \cdot(0,018+0,020+0,025)=0,0315 \mathrm{~mm}
$$

Now, the given value was already within the required range $(0.025 \mathrm{~mm} \ldots 0.035 \mathrm{~mm})$. So, the cause of the elevated temperatures was eliminated.

Although the weaknesses of the repairs were rectified, the experiment had to be stopped due to the Covid-19 epidemic. However, the two-month experiment leads to the following conclusions:

1) The developed device is able to warn about temperature rise.

2) In the absence of previous statistical information, the average temperature accumulated during the month is able to give an idea of the operating temperature of the bearing and when the equipment is in a dangerous technical condition. The average temperature per day summarized in the graph allows the bearing temperature to be understood and monitored most accurately.

\section{Comparison of the device with other types of technical condition control}

The aim of the experiment was not only to test our device, which would be able to monitor the temperature and warn of their rise, but also to find out how effective this method of temperature monitoring is for bearing defects. To find out, the developed device needs to be compared with other types of diagnostics. Therefore, other types of bearing diagnostics were used during the experiment.

\subsection{Vibration measuring device}

The SKF CMAS 100-SL device (Fig. 13a) was used for vibration measurement. This device allows measuring the following parameters [12]:

Vibration velocity $\mathrm{mm} / \mathrm{s}$, amplitude: $0.7 \ldots 65.0 \mathrm{~mm} / \mathrm{s}$;

Temperature ${ }^{\circ} \mathrm{C}$, amplitude: $-20 \ldots+200$ with an error of $\pm 2{ }^{\circ} \mathrm{C}$;

Acceleration gE, amplitude: $0.2 \ldots 50.0 \mathrm{gE}$.

This device has a built-in warning function if any of the parameters are out of range. But in order to work with this device, it must first be adjusted correctly. To do this, you need to know the type of bearing, the diameter of the shaft and the number of revolutions per minute. Measurements were performed both in the radial (Fig. 13b) and axial (Fig. 13c) directions.

The vibrational displacement in the radial direction was $6.6 \mathrm{~mm} / \mathrm{s}$, but in the axial direction $4 \mathrm{~mm} / \mathrm{s}$. Using the manufacturer's table, the warning level was set at $4.5 \mathrm{~mm} / \mathrm{s}$ and at 7.1 $\mathrm{mm} / \mathrm{s}$ for hazardous conditions [11], [12]. It turned out that the vibration is outside the permissible range, but not critical. However, attention had to be paid to and follow the vibrational displacement.

This method is the most accurate way to understand what is happening to the bearing during operation. Because vibration is one of the causes that first indicates defects in bearing rings or rolling bodies and imbalance. 


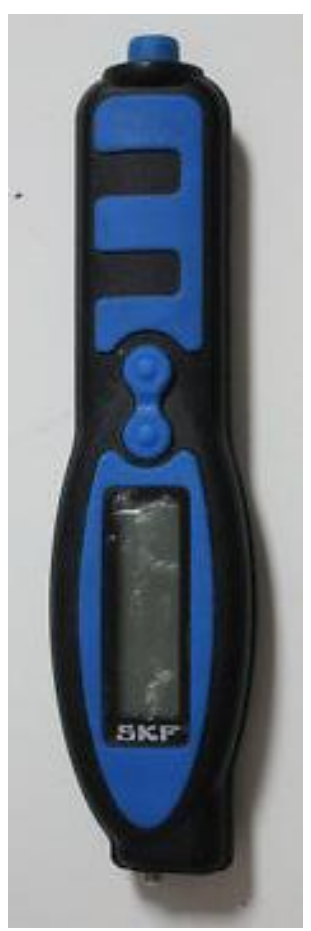

a)

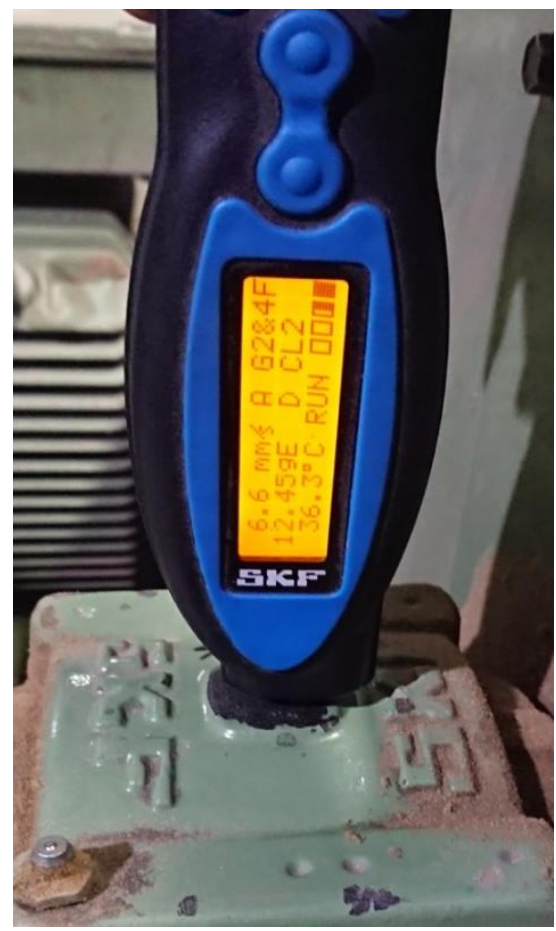

b)

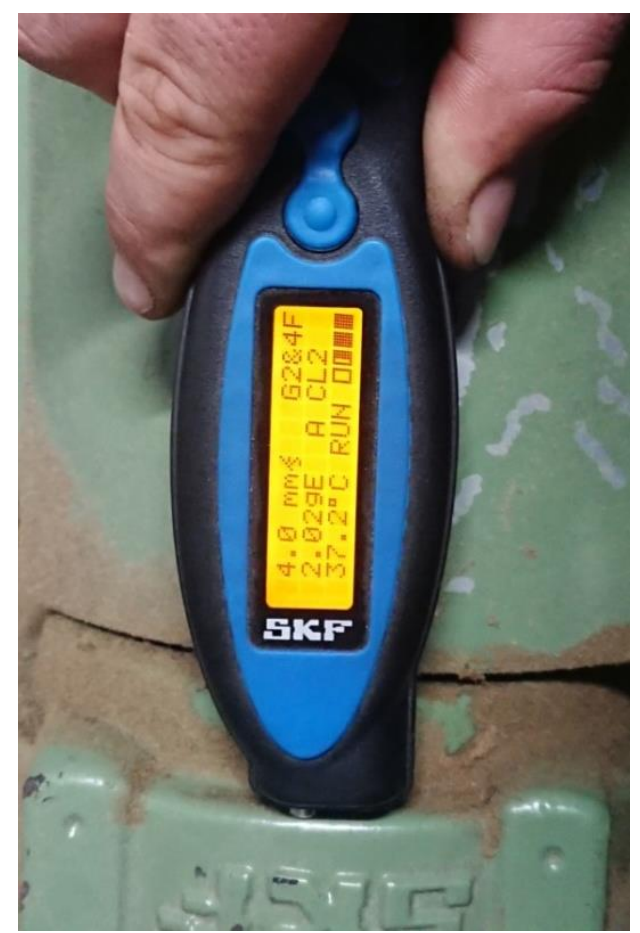

c)

Figure 13. Vibration measurement: a) - measuring device SKF CMAS 100-SL; b) - measurement in the radial direction; c) - measurement in the axial direction.

The advantage of the method is the most accurate result and very little error. Disadvantages include the fact that measurements must be made for each bearing separately. Data must be collected and recorded manually so that you can then watch the trend. Sometimes it is difficult to access the bearing (Fig. 14) or it is dangerous during work. Therefore, the measurements may be inaccurate.

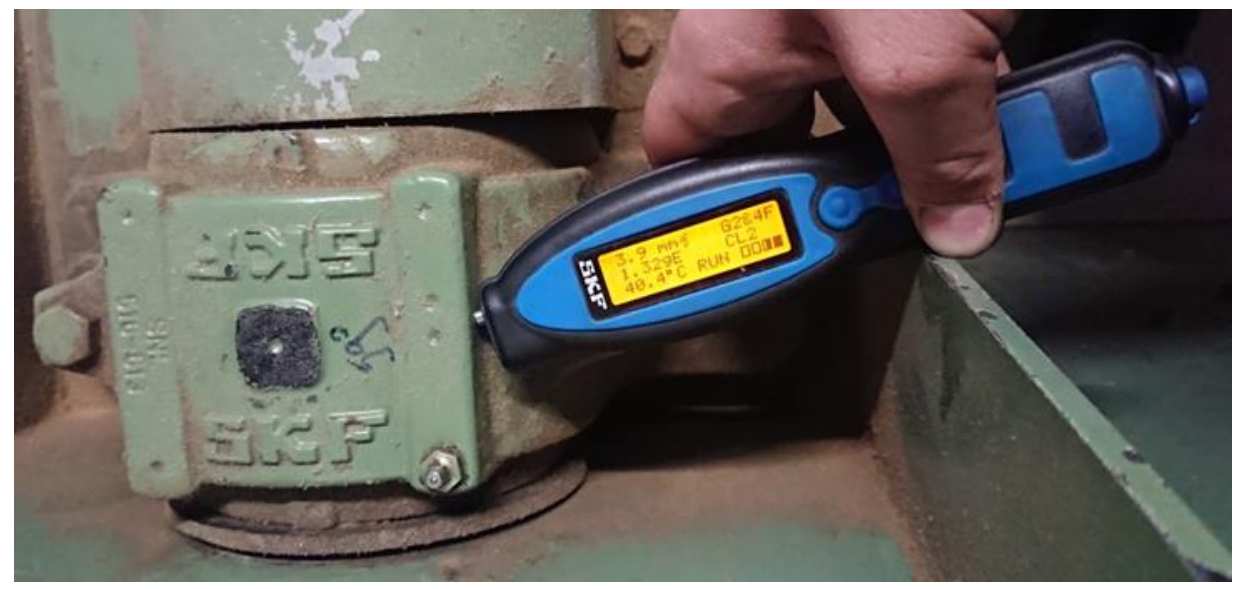

Figure 14. Difficulty accessing the bearing. 


\subsection{Thermal chamber for measuring bearing temperature}

Using a special thermal camera, it is possible to take thermal pictures not only of the bearings, but also of the whole device, including the electric motor and electrical connections. Measurements were performed with a FLIR E5-XT camera at a distance of 1 meter from the bearings. The device parameters are as follows: temperature measuring range: $-20{ }^{\circ} \mathrm{C} \ldots 250$ ${ }^{\circ} \mathrm{C}$, accuracy $( \pm 2 \%)[13]$. In the experiment, the bearings were photographed at work (Fig. $15)$.
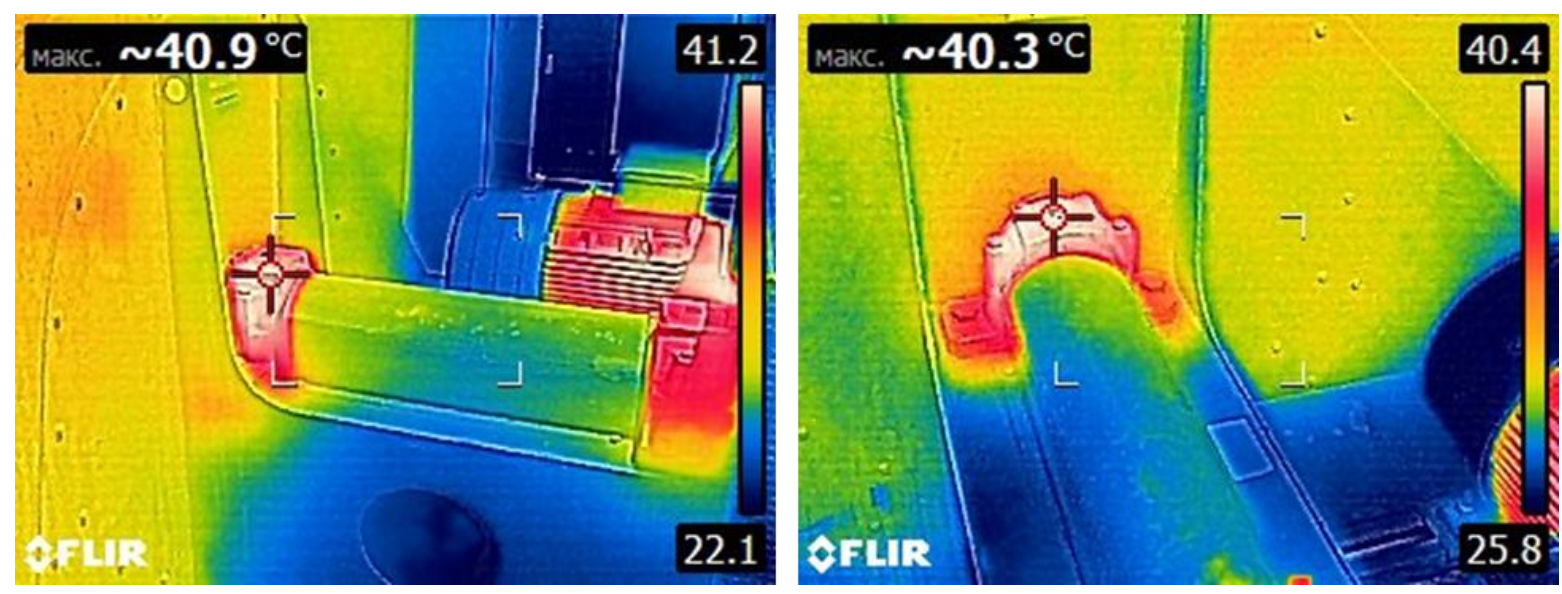

Figure 15. Bearing housing thermal images.

During the experiment, using a thermal chamber, it was possible to better understand how the dissipated heat generated from bearing friction is distributed. It can be observed that most of the heat is dissipated directly through the upper part of the bearing housing (Fig. 15). Most likely, this is due to the fact that the lubrication nipple is located at the top and therefore the most grease is also located at the top, thus creating additional resistance and friction at the top.

The advantage of this method is speed. At the touch of a button, the device takes two pictures: one in colour, the other with heat dissipation. You can then use the computer to compare and archive the pictures. Images can include not only bearings but also other mechanisms such as electric motors and reducers.

The disadvantages are that this method does not allow online temperature monitoring, but only when monitoring has already taken place. This method does not allow seeing the temperature in the outer ring of the bearing, but only on the surface of the bearing housing. This may explain the temperature difference. Our device shows $44{ }^{\circ} \mathrm{C}$, but the thermal camera shows $40^{\circ} \mathrm{C}$.

This method makes it possible to understand the overall condition of the units and to quickly detect a rise in temperature if statistics have been accumulated beforehand.

\subsection{Stethoscope for sound recognition of bearing defects}

The bearing makes a sound when it rotates, and this sound is different for each bearing. The stethoscope allows you to hear possible bearing defects. If you have a lot of experience, then a stethoscope allows you to understand exactly what happened to the bearing. If there is a defect in the inner ring, the sound is more characterized by low frequencies. If the defect is in 
the outer ring, then high frequency sounds are more common. Defects in rollers or balls are characterized by periodicity. This means that this method allows you to know exactly which part of the bearing is damaged.

The electronic stethoscope TMST 3 was used in the experiment (Fig. 16) [14]. As we had no experience, this method showed mixed results during the experiment. The stethoscope manufacturer had given us samples of sound recordings with various bearing defects, but the difference was very difficult to notice. Therefore, this method failed to understand whether the bearing has any defects or not. It is possible that if the bearing has a pronounced defect, it could be heard.

Compared to our device, this method is the most complicated. This method can only be used as an adjunct to other control methods.

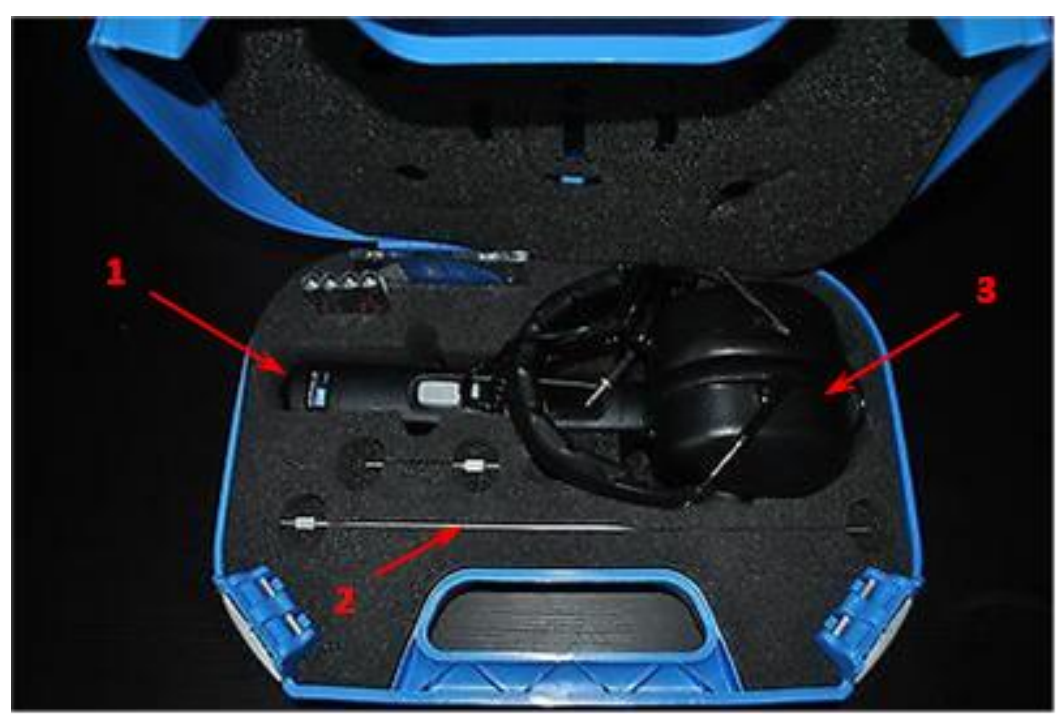

Figure 16. Electronic stethoscope TMST 3:

1 - electronic amplifier; 2 - bar extension; 3 - headphones.

\subsection{Infrared thermometer}

During the experiment, the infrared laser thermometer Testo 805i (Fig. 17) was used. It measured a temperature of about $38^{\circ} \mathrm{C}$. During the experiment, the ambient temperature did not fall below $15^{\circ} \mathrm{C}$, thus the measurement error was $\pm 1.5^{\circ} \mathrm{C}[15]$.

Advantages:

1) Measurements are quick and easy, even if the object to be tested is in a hard-to-reach place.

2) With the phone, measurements can be quickly sent and saved in the form of tables and graphs in Excel format.

Compared to the author's device, an infrared thermometer with data transmission over the phone is the most convenient way to measure the bearing temperature.

However, there are also disadvantages:

1) It cannot monitor the temperature remotely, you have to go to the device every time and take measurements.

2) The temperature of the outer ring of the bearings cannot be measured, but only the temperature of the housing. 
3) The farther the measuring object is, the larger the measurement error and the more it depends on the ambient temperature.

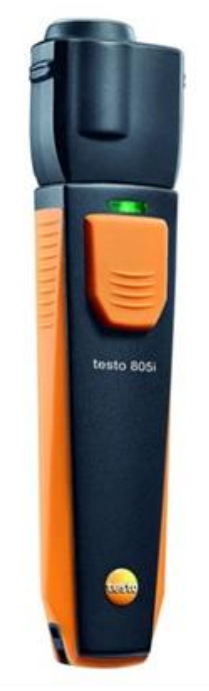

Figure 17. Infrared laser thermometer TESTO 805i.

\section{Results}

Experimental studies have shown that the developed device is able to perform bearing temperature measurements with a certain periodicity and display this information graphically on monitors, as well as to collect data in tabular form and warn of exceeding the operating temperature. The cost of our device did not exceed 8 euros. For comparison, the prices of other manufacturers for this type of devices start from 70 euros. However, experimental tests revealed some shortcomings in the operation of the device.

One of the disadvantages, still, remains the sizes of the device. However, the size can be reduced by using the smallest controller in the Arduino series with Wi-Fi function. The dimensions of the Arduino MKR 1000 controller are $61.5 \mathrm{~mm}$ to $25 \mathrm{~mm}$ (Fig. 18).

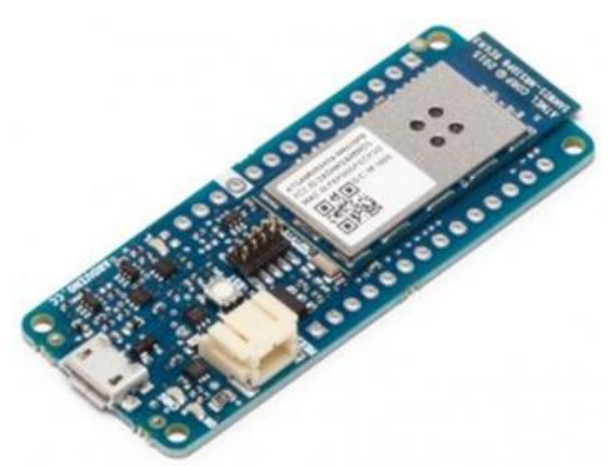

Figure 18. Arduino MKR 1000.

It has been observed that the device may turn off during operation, even when the batteries are charged. This was due to a poor quality controller chip. This can be solved by changing the manufacturer. 
Battery capacity needs to be increased. Currently, the device has $2500 \mathrm{mAh}$ batteries of type 18650 . When measured 4 times a day, the battery life is 25 days. This is a pretty good result, but I would like to increase the working capacity to at least 40 days.

Working capacity can also be increased by removing redundant consumers. For example, you can remove the LED that indicates that the controller is turned on, or you can remove the four LEDs that act as a level indicator from the battery pack. Instead of the indicator, the controller's ability to send data on the state of the battery can be used.

Temperature monitoring is just one of the control methods that have its disadvantages and advantages. The device is quite efficient, as it is possible to collect and store temperature observations over months and in the future also during the year. However, external conditions are variable, and if there is nothing to compare, the measurement results can be misleading. Therefore, in order to better monitor the equipment, it would be better to combine temperature observations with another control method, such as vibration parameter observations.

One way to measure vibration is to use the digital accelerometer ADXL345. The advantages of the proposed accelerometer are related to the fact that it consumes $23 \mu \mathrm{A}$ during the measurement, but in sleep mode $0.1 \mu \mathrm{A}$. The main problem is related to signal sensitivity, because each bearing defect has its own vibration frequency. Therefore, the more accurately it is necessary to assess how dangerous vibration is, the more expensive equipment needs to be purchased. Currently, this issue is still under investigation.

As diagnostic equipment becomes more compact and cheaper today, the idea is to create an integrated bearing control system.

\section{References}

[1] В.М. Кушнаренко, В.С. Репях, Е.Ю. Чирков, Е.В. Кушнаренко: Дефекты и повреждения деталей и конструкций: монография / Оренбургский государственный университет, - Оренбург: ОГУ, УДК 620.19, 2011. - 402 с.

[2] C. Scheffer, P. Girdhar: Practical machinery vibration analysis and predictive maintenance. - Oxford: Wheeler Road, 2008. - 250 pp.

[3] А.И. Власов, П.В. Григорьев, А.И. Кривошеин: Модель предиктивного обслуживания оборудования с применением беспроводных сенсорных сетей.// Надежность и качество сложных систем. № 2 (22). 26-35. (2018). -DOI 10.21685/2307-4205-2018-2-4. УДК 681.324. https://cyberleninka.ru/article/n/modelprediktivnogo-obsluzhivaniya-oborudovaniya-s-primeneniem-besprovodnyh-sensornyhsetey/viewer

[4] В.А. Петин: Проекты с использованием контроллера Arduino. - БХВ-Петербург, ISBN 9785977533379, 2014. - $400 \mathrm{c.}$

[5] Улли Соммер: Программирование микроконтроллерных плат Arduino/Freeduino. БХВ-Петербург, ISBN:978-5-9775-0727-1, 2012. -256 с.

[6] В. Г. Герасимов, О. М. Князьков, А. Е. Краснопольский, В. В. Сухоруков: Основы промышленной электроники. - Москва: Высшая школа, 1978.

[7] Thermocouples: the operating principle. / University Of Cambridge Department of Materials Science \& Metallurgy. https://www.msm.cam.ac.uk/utc/thermocouple/pages/ThermocouplesOperatingPrinciple s.html.

[8] Thermometrics. Type K Thermocouple. /Thermometrics. https://www.thermometricscorp.com/thertypk.html. 
[9] Dallas Semiconductor. DS18B20 DataSheet. / Dallas Semiconductor. https://html.alldatasheet.com/htmlpdf/227472/DALLAS/DS18B20/216/1/DS18B20.html

[10] 22313 EK | SKF https://www.skf.com/group/products/rolling-bearings/rollerbearings/spherical-roller-bearings/productid-22313\%20EK

[11] Evaluation of vibration. /IMV CORPORATION. https://www.imv.co.jp/e/pr/vibration_measuring/chapter04/

[12] SKF Machine Condition Advision. CMAS 100-SL. https://docs.rs-online.com/14c1/A700000006637740.pdf

[13] FLIR Ex-Series Datasheet. / FLIR Systems. https://www.flir.com/globalassets/imported-assets/document/ex-series-no-wifidatasheet.pdf

[14] SKF Electronic Stethoscope TMST 3. https://www.skf.com/binaries/pub12/Images/0901d1968008a5f014376EN_TMST3 tcm_12-35822.pdf

[15] Infrared thermometer operated with smartphone testo 805i. /TESTO. http://www.farnell.com/datasheets/2182287.pdf 